Ageing in Europe - Supporting policies for an inclusive society 


\section{Ageing in Europe - Supporting policies for an inclusive society}

Edited by

Axel Börsch-Supan, Thorsten Kneip, Howard Litwin, Michat Myck and Guglielmo Weber

\section{DE GRUYTER}


This work has been funded by the German Federal Ministry of Education and Research, the European Commission, the US National Institute on Aging and other national funders (for details see p. $18 \mathrm{ff}$ ). The responsibility for the content lies with the authors.

ISBN 978-3-11-044412-4

e-ISBN (PDF) 978-3-11-044441-4

e-ISBN (EPUB) 978-3-11-043704-1

\section{(c) BY-NC-ND}

This work is licensed under the Creative Commons Attribution-NonCommercial-NoDerivs 3.0 License. For details go to http://creativecommons.org/licenses/by-nc-nd/3.0/.

\section{Library of Congress Cataloging-in-Publication Data}

A CIP catalog record for this book has been applied for at the Library of Congress.

\section{Bibliographic information published by the Deutsche Nationalbibliothek}

The Deutsche Nationalbibliothek lists this publication in the

Deutsche Nationalbibliografie; detailed bibliographic data are available in the Internet at http://dnb.d-nb.de.

(c) 2015 Walter de Gruyter GmbH \& Co. KG, Berlin/Boston

The book is published with open access at www.degruyter.com.

Typesetting: Medien Profis GmbH, Leipzig

Printing: Hubert \& Co. GmbH \& Co. KG, Göttingen

(2) Printed on acid-free paper

Printed in Germany

www.degruyter.com 


\title{
Contents
}

\author{
Editors - IX
}

Contributors $-\mathrm{X}$

Axel Börsch-Supan, Thorsten Kneip, Howard Litwin, Michat Myck and Guglielmo Weber

1 SHARE: a European policy device for inclusive ageing societies - 1

\section{Part I Material deprivation and social exclusion - extending analysis using Wave 5 data \\ Edited by Michat Myck}

Maja Adena, Michał Myck and Monika Oczkowska

2 Material deprivation items in SHARE Wave 5 data: a contribution to a better understanding of differences in material conditions in later life -25

Kimberly J. Stoeckel and Howard Litwin

3 Accessibility to neighbourhood services and well-being among older Europeans - 39

Marco Bertoni, Danilo Cavapozzi, Martina Celidoni and Elisabetta Trevisan

4 Assessing the material deprivation of older Europeans - 49

Marco Bertoni, Danilo Cavapozzi, Martina Celidoni and Elisabetta Trevisan

5 Development and validation of a material deprivation index - 57

Michat Myck, Mateusz Najsztub and Monika Oczkowska

6 Measuring social deprivation and social exclusion - 67

Mateusz Najsztub, Andrea Bonfatti and Dominika Duda

7 Material and social deprivation in the macroeconomic context -79

\section{Part II Deprivation and social exclusion: causes and implications \\ Edited by Thorsten Kneip}

Marco Bertoni, Martina Celidoni and Guglielmo Weber

8 Does hearing impairment lead to social exclusion? - 93

Roméo Fontaine, Maribel Pino, Marine Jean-Baptiste, Aurore Philibert, Nicolas Briant and Marie-Eve Joël

9 Older adults living with cognitive and mobility-related limitations: social deprivation and forms of care received -103 
Hannes Kröger and Rasmus Hoffmann

10 Who can realise their retirement plans? Poor health and employment crises as factors of exclusion -115

Stefan Listl and Hendrik Jürges

11 Social inequalities in oral health - towards targeted health policy interventions -127

Fabio Franzese

12 Slipping into poverty: effects on mental and physical health 139

Kimberly J. Stoeckel and Howard Litwin

13 Social cohesiveness and neighbourhood environmental deprivation: how are they related to life satisfaction in late life? - 149

\section{Part III Inclusion and social cohesiveness}

Edited by Howard Litwin

Christian Deindl and Martina Brandt

14 Social exclusion and support between generations - 161

Sharon Shiovitz-Ezra

15 Loneliness in Europe: do perceived neighbourhood characteristics matter? 169

Melanie Wagner and Martina Brandt

16 Loneliness among informal caregivers aged 50+ in Europe -179

Andrej Srakar, Maša Filipovič Hrast, Valentina Hlebec and Boris Majcen

17 Social exclusion, welfare regime and unmet long-term care need: evidence from SHARE 189

Christian Hunkler, Thorsten Kneip, Gregor Sand and Morten Schuth

18 Growing old abroad: social and material deprivation among first- and second-generation migrants in Europe -199

Liudmila Antonova, Luis Aranda, Enkelejda Havari and Noemi Pace

19 Is there a European land of opportunity? Cross-country differences in intergenerational mobility in 14 European countries and Israel -209 


\section{Part IV Employment, social inclusion and social protection}

Edited by Axel Börsch-Supan

Andrea Bonfatti, Martina Celidoni and Guglielmo Weber

20 Coping with risks during the Great Recession — 225

Flavia Coda Moscarola, Anna Cristina d'Addio, Elsa Fornero and Mariacristina Rossi

21 Reverse mortgage: a tool to reduce old age poverty without sacrificing social inclusion -235

Mauro Mastrogiacomo and Michele Belloni

22 Becoming self-employed at ages 50+: true entrepreneurship or exclusion from (wage-)employment? 245

Michele Belloni, Agar Brugiavini, Elena Meschi and Giacomo Pasini

23 Does training help retaining older workers into employment?

Evidence from the SHARE survey -257

Axel Börsch-Supan, Benedikt Alt and Tabea Bucher-Koenen

24 Early retirement for the underprivileged? Using the record-linked SHARE-RV data to evaluate the most recent German pension reform — 267

Danilo Cavapozzi, Elisabetta Trevisan and Guglielmo Weber

25 The use of PC at work and job satisfaction -279

\section{Part V Health and health care}

Edited by Guglielmo Weber

Aviad Tur-Sinai and Howard Litwin

26 Forgone visits to the doctor due to cost or lengthy waiting time among older adults in Europe -291

Hendrik Jürges

27 Health insurance coverage and access to care among European elders: cross-national differences and social gradients - 301

Enrica Croda

28 Pain and social exclusion among the European older people - 313

Radim Bohacek, Laura Crespo, Pedro Mira and Josep Pijoan-Mas

29 The educational gradient in life expectancy in Europe: preliminary evidence from SHARE — 321 
Anne Laferrère and Karel Van den Bosch

30 Unmet need for long-term care and social exclusion - 331

Ludovico Carrino and Cristina Elisa Orso

31 Eligibility regulations and formal home-care utilisation among the vulnerable older people in SHARE Wave $5-343$

Tabea Bucher-Koenen, Johanna Schütz and Martin Spindler

32 Long-term care insurance across Europe - 353

Eric Bonsang and Jérôme Schoenmaeckers

33 Long-term care insurance and the family: does the availability of potential caregivers substitute for long-term care insurance? - 369 


\section{Does training help retaining older workers into employment? Evidence from the SHARE survey}

\footnotetext{
Training helps keeping older workers in employment, by reducing human capital depreciation

- There is a clear nexus between lower pensions and/or early retirement and material and social deprivation in old age. Therefore, it is only by making it feasible to retain older workers in the labour market that we can ensure higher well-being
}

\subsection{Training and employment of older workers}

The long-term increase in longevity, coupled with the progressive compression of morbidity experienced in Europe in the last decades, improved the well-being of many older individuals. However, a failure to adjust the retirement age has exposed poor households to financial distress (Angelini et al. 2009).

Staying longer in the labour force may be a solution to preserve an adequate level of resources and limit the risk of economic deprivation, it is also an effective mean to maintain social ties and foster an active life. However, working longer requires investment in human capital over the life cycle (Mahyew \& Rjkers 2004), as acquired skills become obsolete as time goes by. The rapid technological progress prevailing in many sectors makes training the older workforce the only effective policy to prevent skills obsolescence (Bishop 1997, Belloni \& Villosio 2014).

The aim of this chapter is to investigate whether participation in training helps keeping older workers (aged 50-65) in employment. In particular, we use Wave 4 and Wave 5 of SHARE to test the effect of training participation in 2010 (Wave 4) on changes in labour market status between 2010 and 2012 (Wave 5), controlling for a rich set of observable individual characteristics. Information on self-reported current economic status allows us to distinguish between six labour force states: employed or self-employed, unemployed, permanently sick or disabled, retired, homemaker and "other". To measure training participation we exploit a question in Wave 4 (part of the module "Activities") which asks respondents whether they attended any educational or training course in the last twelve months. 
The main result of this chapter is that individuals who took part in training activities in the year prior to the 2010 (2009 for Estonia) interview are significantly less likely to leave the labour market. Training older workers may therefore prevent them from being exposed to the risk of poverty and social exclusion. This chapter is organised as follows: the next section reports the descriptive evidence regarding labour market status in the last two waves of SHARE and participation in training activities. The following section presents the results of a multivariate analysis, which aims at capturing the effect of training on the probability of exiting the labour market. The last section concludes the chapter, providing some policy implications of our analysis.

\subsection{Descriptive analysis}

Table 23.1 reports aggregate labour market status by wave and age group. Figures referring to the total sample ("Wave 4: Total; Wave 5: Total") are very similar across waves: around 30 per cent of the sample reports to be in the labour force (either employed, self-employed or unemployed), 57 per cent to be retired, 3.6 per cent to be disabled and nine per cent are in "other" status (which includes homemakers). The labour force participation rate among individuals aged 50-65 was 55 per cent in Wave 4; this figure is similar to what found using previous waves of SHARE (see Meschi et al. 2013, Brugiavini et al. 2008). The fraction of people in the labour force in Wave 5 in the same age range is instead higher (60 per cent). As regards the age $65+$ category, numbers are very similar between waves $(2.6 \%$ in Wave 4; $3 \%$ in Wave 5). Finally, it is worth mentioning that the sample size is higher in Wave 5 than in Wave 4 due to the way in which refresher samples have been collected in the different countries. In this chapter, we aim at analysing the determinants of transitions out of employment between 2010 and 2012, devoting special attention to the role of training. Therefore, we focus on the subsample of 16,028 individuals aged 50-65 and in labour force in $2010 .^{1}$

1 We exclude 706 individuals aged 65+ in Wave 4 since statutory retirement age across Europe is generally lower than 67 , i.e. their age in Wave 5. In any case, we repeated the analysis on the full sample and results are virtually unchanged. 
Table 23.1: Labour market status by age groups (Waves 4 and 5)

\begin{tabular}{llllllll}
\hline & \multicolumn{5}{c}{ Wave 4 } & \multicolumn{3}{c}{ Wave 5 } \\
\cline { 2 - 8 } & & age 50-65 & age $>65$ & Total & age 50-65 & age >65 & Total \\
\hline Retired & $\mathrm{N}$ & 8,828 & 23,687 & 32,515 & 7,661 & 28,213 & 35,874 \\
& $\%$ & 30.11 & 87.22 & 57.57 & 25.03 & 87.01 & 56.91 \\
\hline In labour force & $\mathrm{N}$ & 16,028 & 706 & 16,734 & 18,239 & 963 & 19,202 \\
& $\%$ & 54.66 & 2.6 & 29.63 & 59.58 & 2.97 & 30.46 \\
\hline Disabled & $\mathrm{N}$ & 1,855 & 225 & 2,080 & 1,945 & 309 & 2,254 \\
& $\%$ & 6.33 & 0.83 & 3.68 & 6.35 & 0.95 & 3.58 \\
\hline Other & $\mathrm{N}$ & 2,610 & 2,539 & 5,149 & 2,766 & 2,940 & 5,706 \\
& $\%$ & 8.9 & 9.35 & 9.12 & 9.04 & 9.07 & 9.05 \\
\hline Total & $\mathrm{N}$ & 29,321 & 27,157 & 56,478 & 30,611 & 32,425 & 63,036 \\
& $\%$ & 100 & 100 & 100 & 100 & 100 & 100 \\
\hline
\end{tabular}

Source: SHARE Wave 4 release 1.1.1, Wave 5 release 0

Table 23.2 shows labour market status in Wave 5 of individuals who were in the labour force in Wave 4, distinguishing between those who attended training activities in 2010 and those who did not. About 6,000 selected individuals interviewed in Wave 4 did not participate in Wave 5: this leads to a final sample of 10,725 individuals aged 50-65 in Wave 4 for which we observe labour market status in both waves. About 27 per cent of them $(2,912)$ took part to training activities. The following facts emerge from the table: 79 per cent of those who did not undertake training were still in the labour force, whereas this percentage is equal to 86 per cent for those who did undertake training. Conversely, the percentage of new retirees is equal to $15 \mathrm{per}$ cent between the non-trained and to ten per cent between trained workers.

Table 23.2: Labour market status in Wave 5 by training participation in Wave 4: individuals aged 50-65 in labour force in Wave 4

\begin{tabular}{llllll}
\hline \multicolumn{7}{c}{ Labour market status in Wave 5 } & & \\
\cline { 2 - 6 } & Retired & In labour force & Disabled & Other & Total \\
\hline & \multicolumn{2}{l}{ Participation in training: NO } & & & \\
\hline In labour force in & 1,186 & 6,172 & 211 & 244 & 7,813 \\
Wave 4 & 15.18 & 79 & 2.7 & 3.12 & 100 \\
\hline & Participation in training: YES & & & \\
\hline In labour force in & 313 & 2,498 & 39 & 62 & 2,912 \\
Wave 4 & 10.75 & 85.78 & 1.34 & 2.13 & 100 \\
\hline
\end{tabular}

Source: SHARE Wave 4 release 1.1.1, Wave 5 release 0 
Figure 23.1 reports the wide variability of training incidence by country and Figure 23.2 shows the relationship between training incidence in Wave 4 and the percentage of individuals aged 60 or more who are in employment in Wave 5. Prima facie evidence suggests a clear positive association between participation in training programmes and labour force participation, as well as a wide cross-country heterogeneity in the incidence of training. In order to control for other determinants of labour force mobility we carry out a multivariate analysis.

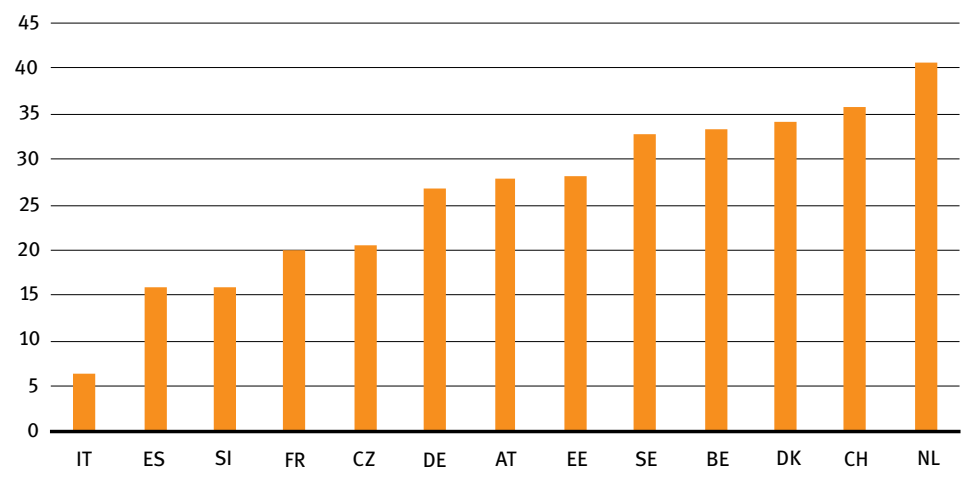

Figure 23.1: Training participation by country (percentage of people that attended an educational or training course in the twelve months before the interview) Notes: The figure is based on individuals who were in employment in Wave 4 Notes: 14,385 observations

Source: SHARE Wave 4 release 1.1.1

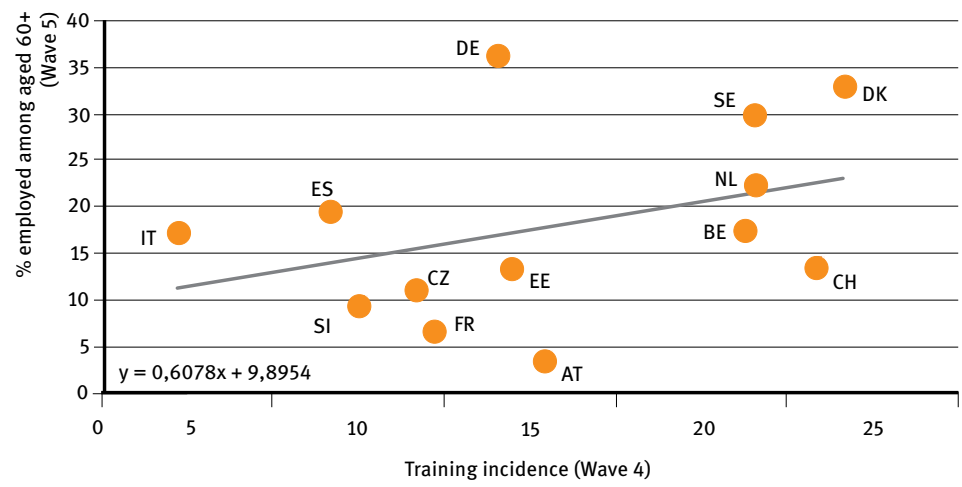

Figure 23.2: Training participation in Wave 4 and percentage of employed among people aged 60 or more in Wave 5 , by country

Notes: 47,248 observations

Source: SHARE Wave 4 release 1.1.1, Wave 5 release 0 


\subsection{Multivariate analysis}

Table 23.3 reports the results from several specifications of a Linear Probability Model. All individuals included in the analysis were employed in Wave 4 and took part to both waves. The dependent variable takes value "1" if the individual is not employed in Wave 5, value " 0 " otherwise. Our variable of interest (Attended an educational or training course) is a dummy equal to " 1 " if the individual took part to a training activity in the year prior to the interview in Wave 4, value " 0 " otherwise.

Column (1) only includes a basic set of control variables, i.e. a full set of dummies for age, educational attainment (ISCED categories), gender, marital status and self-reported health status, plus family composition variables and the logarithm of total household income. In column (2), we additionally control for a full set of occupational dummies (9 variables referring to 1-digit ISCO codes, see ILO (2012)), while in column (3) we also add country fixed effects.

Table 23.3: Linear probability model. dependent variable: transition out of employment between Wave 4 and 5

\begin{tabular}{|c|c|c|c|c|c|}
\hline VARIABLES & $\begin{array}{l}(1) \\
\text { OLS }\end{array}$ & (2) & (3) & $\begin{array}{l}(4) \\
\text { IV }\end{array}$ & $\begin{array}{l}\text { (5) } \\
\text { (first stage) }\end{array}$ \\
\hline $\begin{array}{l}\text { Attended an educational } \\
\text { or training course }\end{array}$ & $\begin{array}{l}-0.042^{\star \star \star} \\
{[0.008]}\end{array}$ & $\begin{array}{l}-0.037^{\star \star \star} \\
{[0.008]}\end{array}$ & $\begin{array}{l}-0.027^{\star \star \star} \\
{[0.008]}\end{array}$ & $\begin{array}{c}-0.431^{\star} \\
{[0.231]}\end{array}$ & - \\
\hline Dummy ISCO & No & Yes & Yes & Yes & Yes \\
\hline Dummy countries & No & No & Yes & Yes & Yes \\
\hline \multicolumn{6}{|l|}{ Exclusion restrictions: } \\
\hline firm size class & - & - & - & & $\begin{array}{l}0.021^{\star \star \star} \\
{[0.007]}\end{array}$ \\
\hline $\begin{array}{l}\text { Wu-Hausman Ho: variables } \\
\text { are exogenous ( } \mathrm{p} \text {-value) }\end{array}$ & & & & 0.0577 & \\
\hline Observations & 9,472 & 9,331 & 9,331 & 8,260 & 8,260 \\
\hline
\end{tabular}

Notes: Robust standard errors in brackets; IV first stage: clustered standard errors; ${ }^{\star \star \star} p<0.01$, ${ }^{\star} * p<0.05,{ }^{\star} p<0.1$. Basic controls: dummies for age, female, educational attainment (ISCED groups), being single, self-reported health status (scale 1 to 5); number of grandchildren; number of children; log of total household' income. All regressions include a constant. In the IV regression, the instrument is the median firm size by country and industry (computed from the EU-LFS). In columns (4) and (5) observations from Switzerland are excluded since the instrument is not available for non-EU countries.

Source: SHARE Wave 4 release 1.1.1, Wave 5 release 0 
Looking at column (1), we can see that the effect of training is statistically significant, precisely estimated and sizeable: those who undertook training activities have a 4.2 per cent lower probability to move out of employment. Other variables (not reported) have the expected sign: older and less healthy individuals are more likely to move out of employment; there is a clear and statistically relevant gradient between education and labour market attachment, while income is not statistically significant, perhaps because the education dummies already capture the effect of economic resources. Pension eligibility rules are country specific, but in most European countries, they depend on the type of occupation. This is also true for professional training: in fact, once we control for a full set of occupational dummies in column (2), the coefficient of interest decreases to -0.037 , i.e. taking part in a training activity reduces the chances of being out of employment in 2012 by 3.7 percentage points. Managers, professionals, technicians and clerks are less likely to be out of employment in 2012 compared to those employed in elementary occupations. It is worth noting that the question about training does not allow to distinguish between on-the-job training and training individuals undertook while unemployed, e.g. as part of an active labour market policy. Respondents were asked whether they took part to a training activity in the previous 12 months, without any reference to their labour market status at the time of the training. Still, the vast majority of people reporting being employed in Wave 4 (95\%) also report to have been continuously working in the previous year. As we already pointed out in the previous section, there are stark differences in participation in training programmes across countries. This means the coefficient of the training dummy may reflect institutional differences in training policies rather than on differences in individual decisions. In column (3) we therefore include a full set of country dummies. In this specification, the coefficient of interest further reduces to -0.027: an important fraction of the association between training participation and labour force participation can be explained by institutional differences across countries, but still we can observe a statistically significant association even controlling for country differences.

Specifications (1)-(3) provide estimates of the potential effect of training based on the method of ordinary least squares (OLS), which measures the associations between training participation and later employment net of the effect of a number of confounding factors. However these estimates do not necessarily identify a causal relation as they may suffer of endogeneity due to reverse causality: rational individuals plan their retirement well in advance, accounting for their preferences and policy incentives to anticipate or postpone retirement. The decision to work beyond a given age requires that skills are preserved for a longer period. Therefore, engagement in training activities by older workers may be induced by their retirement plans. 
In order to tackle this issue, we run an instrumental variable (IV) analysis. A valid instrument must correlate with the regressor of interest, which is participation in training in our case, but must be unrelated to unobservable determinants of employment participation. In other words, a valid and informative instrument should affect employment participation in 2012 only through its effect on training in 2010. The chosen instrument is the median firm size class by industry and country. This instrumental variable is constructed using data from the 2009 Wave of the European Union Labour Force Survey (EU-LFS), which is a large crosssectional household sample survey coordinated by Eurostat. EU-LFS contains information on firm size, aggregated in the following four classes: 1 to 10 persons; 11 to 19 persons; 20 to 49 persons; 50 persons or more. Firm size is likely to affect the probability of participating in training: on the one hand, larger firms have more structured human resource management policies and relatively more resources to devote to personnel development and might find less difficult to replace a worker who temporarily leaves for training (see for example Bassanini et al. 2005). On the other hand, the European Union adopted in June 2008 the "Small business Act for Europe", a document that reflects the Commission's political will to put into place a comprehensive SME policy framework for the EU and its Member States. Professional training and human capital development where central topics in the Competitiveness and Innovation Framework Programme and other EU funding programmes.

Columns (4)-(5) of Table 23.3 present the result of the IV estimates. The Hausman test reported at the bottom of column (4) confirms the need for an IV approach: it is not possible to exclude the endogeneity of training at the 95 per cent significance level. Once estimated with the IV procedure, the coefficient of training is positive and bigger than in the OLS estimation (see column 4). One could expect OLS estimates to be upward-biased due to reverse causation. Still, caution is required in the interpretation of the magnitude of the coefficient of interest because of the low precision of the estimates. Note, however, that the lack of precision cannot be imputed to a "weak instrument" problem: the first stage estimation reported in column (5) shows that the instrument has strong significant explanatory power. Finally, results are virtually unchanged if we consider the mean rather than the median size in order to classify firms into small, medium and large.

One potential threat to the validity of the proposed analysis comes from the fact that in none of the regressions we control for the industry sector. The sector correlates with firm size and is one of the sources of variability of the instrument we propose: results are valid if the sector does not have an independent direct effect on the employment decision. In order to test this assumption, we run an OLS regression similar to (3) but also including a set of dummies accounting for 
the economic sector (according to NACE coding) in which the respondent was employed in Wave 4. The training coefficient changes only at the third decimal figure. This result is backed up by results of F-tests on no joint significance of the NACE sector dummies (F-statistic in OLS specification 0.0107, p-value 0.80; F-statistic in IV specification 0.0619, p-value 0.67). We run a number of further robustness checks and different specifications: we re-run the analysis by including first broader age-ranges and then narrower age-ranges, compared to the 50-65 age-range of the baseline. We used a less data demanding linear and polynomial specification in age rather than a full set of dummies. Finally, we excluded individuals who were working in 2010 and reported to be homemakers or disabled in 2012. In all those cases, the estimated coefficient for participation in training is virtually unchanged.

\subsection{Older workers' training policies and well-being}

In this chapter, we investigated whether participation in training helps keeping older workers in employment. We relate participation in training activities in 2010 (SHARE Wave 4) to changes in labour market status between 2010 and 2012 (SHARE Wave 5). We find that workers engaged in training are more likely to remain in employment two years later.

Our results provide evidence that continuous education reduces human capital depreciation and increases employability of older workers. Since there is a clear nexus between lower pensions and/or early retirement and material and social deprivation in old age, we argue that the risk of falling into poverty in old age would be reduced thanks to the adoption of training policies, which help to retain older workers in the labour market.

\section{References}

Angelini, Viola, Brugiavini, Agar, Weber, Guglielmo (2009): “Ageing and unused capacity in Europe: is there an early retirement trap?". In: Economic Policy 24, p. 463-508.

Bassanini, Andrea, Booth, Alison, Brunello, Giorgio, De Paola, Maria, Leuven, Edwin (2005):

“Workplace training in Europe". In: IZA Discussion Papers 1640, Institute for the Study of Labor (IZA).

Belloni, Michele, Villosio, Claudia (2015): “Training and wages of older workers in Europe”. In:

European Journal of Ageing, special section: Work and Retirement 12(1), p. 7-16.

Bishop, John (1997): "What we know about employer-provided training: a review of the literature”. In: Research in Labor Economics 16, p. 19-87. 
Brugiavini, Agar, Pasini, Giacomo, Peracchi, Franco (2008): "Exit from the labour force". In: Börsch-Supan, Axel, Brugiavini, Agar, Jürges, Hendrik, Mackenbach, Johan, Siegrist, Johannes, Weber, Guglielmo (Eds.): First results from the Survey of Health, Ageing and Retirement in Europe (2004-2007). Mannheim: Mannheim Research Institute for the Economics of Aging (MEA), p. 206-214.

Gruber, Jonathan, Wise, David (2004): Social security programs and retirement around the world: micro-estimation. Chicago: National Bureau of Economic Research, University of Chicago Press.

ILO (2012): "International Standard Classification of Occupations: Structure, group definitions and correspondence tables". Geneve, Volume 1.

Meschi, Elena, Pasini, Giacomo, Padula, Mario (2013): “Economic crisis and pathways to retirement”. In: Börsch-Supan, Axel, Brandt, Martina, Litwin, Howard, Weber, Guglielmo (Eds.): Active ageing and solidarity between generations in Europe, Berlin: DE GRUYTER, p. 101-109.

Mahyew, Ken, Rjkers, Bob, (2004): “How to improve the human capital of older workers or the sad tale of the magic bullet". Paris: OECD.

OECD (2006): "Live Longer, Work longer”. Paris.

Picchio, Matteo, van Ours, Jan (2013): "Retaining through training even for older workers", In: Economics of Education Review 32, p. 29-48. 
